\title{
Preparation, electrical contact performance and arc-erosion behavior of $\mathrm{Cu} / \mathrm{La}_{2} \mathrm{NiO}_{4}$ composites
}

\author{
Yongli Guo ${ }^{a}{ }^{*}$, Zhibin Zhou ${ }^{b}$ and Yaping Wang ${ }^{c}$ \\ MOE Key Laboratory for Nonequilibrium Synthesis and Modulation of Condensed Matter, School of \\ Science, Xi'an Jiaotong University, Xi'an 710049, PR China \\ agyl89307@163.com, b 1225579932@qq.com, c ypwang@mail.xjtu.edu.cn
}

Keywords: $\mathrm{Cu}$ matrix composites, $\mathrm{La}_{2} \mathrm{NiO}_{4}$ ceramics, Contacts, Electrical properties, Arc erosion Abstract. $\mathrm{La}_{2} \mathrm{NiO}_{4}$ conductive particles were incorporated into $\mathrm{Cu}$ matrix for enhanced electrical contact performance, while their effect on the arc erosion behavior of contacts was investigated. The results indicate that the particles in the hot-pressed $\mathrm{Cu} / \mathrm{La}_{2} \mathrm{NiO}_{4}$ composites accelerate the separation of oxide scales from contact surface during arc erosion cycling, suggested by increased mass loss of roughly 3 to 9 times larger than pure $\mathrm{Cu}$. Thus, the growth of oxide scales on contact surface was blocked by a self-cleaning-like function. As a result, the contact resistance declines to $21.6 \mathrm{~m} \Omega$ after 5000 cycles, in contrast with $29.5 \mathrm{~m} \Omega$ for $\mathrm{Cu}$, and correspondingly the temperature rise degrades about $30.7 \%$.

\section{Introduction}

In long-term service, oxide scales involving $\mathrm{CuO}$ and $\mathrm{Cu}_{2} \mathrm{O}$ are generated on $\mathrm{Cu}$ contact surface due to the arc-erosion-derived effects during turning on and off contact pairs in air; and therefore, the growth of the low-conductive scale layers results in the development of high contact resistance, potentially leading to performance deterioration or failure of devices [1]. To strengthen $\mathrm{Cu}$ for electrical contact applications, alloying is an effective approach, e.g., $\mathrm{Cr}, \mathrm{W}$ for $\mathrm{Cu}$ contacts in vacuum interrupters [2,3]. Anidow et al. [4] alloyed $\mathrm{Cu}$ with 9 at.\% La to reduce the contact resistance through doping cuprous oxide. But introducing alloying elements remarkably weakens the bulk conductivity of $\mathrm{Cu}$ base [5]. The reinforcements like $\mathrm{Al}_{2} \mathrm{O}_{3}, \mathrm{ZnO}$, and $\mathrm{Y}_{2} \mathrm{O}_{3}$ powders are also incorporated into $\mathrm{Cu}$ to enhance arc erosion resistance; nevertheless, the maximum bulk conductivity only approximating to $80 \%$ IACS are obtained by adding $4 \mathrm{wt} . \% \mathrm{ZnO}$ particles [6].

In this work, we prepared novel $\mathrm{Cu}$ contact materials for low-voltage switches by incorporating 5 wt. $\% \mathrm{La}_{2} \mathrm{NiO}_{4}$ ceramic particles with electrical conductivity close to metals [7], not only to preserve high bulk conductivity of $\mathrm{Cu}$ base, but also to improve the electrical contact performance via a self-cleaning-like surface that can induce accelerated separation of scale from contact surface during circuit opening and closing.

\section{Experimental}

Preparation of Samples. $\mathrm{La}_{2} \mathrm{NiO}_{4}$ powders were synthesized through a sol-gel strategy that both $\mathrm{Ni}\left(\mathrm{NO}_{3}\right)_{2}$ and $\mathrm{La}\left(\mathrm{NO}_{3}\right)_{3}$ were used as precursors, as shown in detail in Ref. [8]. The synthesized sol was heated at $130{ }^{\circ} \mathrm{C}$ to transform to dry gel, and sintered at $850{ }^{\circ} \mathrm{C}$ to form crystalline $\mathrm{La}_{2} \mathrm{NiO}_{4}$ particles. Next, $\mathrm{La}_{2} \mathrm{NiO}_{4}$ powders with a content of $5 \mathrm{wt} \%$ were homogeneously mixed with commercially elemental $\mathrm{Cu}$ powders $(99.5 \%,<45 \mu \mathrm{m})$. The blended powders were cold-pressed at $600 \mathrm{MPa}$, and then sintered at $980{ }^{\circ} \mathrm{C}$ in vacuum furnace, accompanied with a densification process that was hot-pressed at $750{ }^{\circ} \mathrm{C}$ and $50 \mathrm{MPa}$ for $20 \mathrm{~min}$, so as to obtain densely bulk $\mathrm{Cu} / \mathrm{La}_{2} \mathrm{NiO}_{4}$ composites. For comparison, pure $\mathrm{Cu}$ ones were fabricated in the same way.

Characterization of Samples. The phases of materials were determined by D8-ADVANCE X-ray diffractometer (XRD). A JSM-7000F field-emission scanning electron microscope (FESEM) was applied to observe the microstructures. The electrical conductivity was measured by Sigma2008A 
eddy current conductivity meter. The arc erosion test was performed on a device like that shown in Ref. [6,9], using $\Phi 6 \mathrm{~mm} \times 12 \mathrm{~mm}$ sized-samples for both upper (fixed) and lower (movable) contacts. The test was operated by continually switching on and off 1000, 2000, 3000, 4000 and 5000 cycles at parameters of AC current $10 \mathrm{~A}$, contact gap $4 \mathrm{~mm}$ and contact force $3 \mathrm{~N}$. For per 1000 cycles, the mass of both upper and lower contacts were measured to obtain the total mass loss; and the contact resistance was measured via voltage-ampere method at $\mathrm{DC}$ current of $1 \mathrm{~A}$, while the temperature rise was determined in the conditions of AC current $10 \mathrm{~A}$, contact force $3 \mathrm{~N}$ and contact time 30 min.

\section{Results and Discussion}

Phase and Morphology of $\mathrm{La}_{2} \mathrm{NiO}_{4}$ Particles. Fig. 1 shows the XRD pattern of the synthesized $\mathrm{La}_{2} \mathrm{NiO}_{4}$ powders, suggesting crystalline $\mathrm{La}_{2} \mathrm{NiO}_{4}$ as main component for its high electrical conductivity, and a little residual $\mathrm{La}\left(\mathrm{NO}_{3}\right)_{3}$ precursor. The irregularly shaped particles demonstrate sizes less than $10 \mu \mathrm{m}$ (the inset).

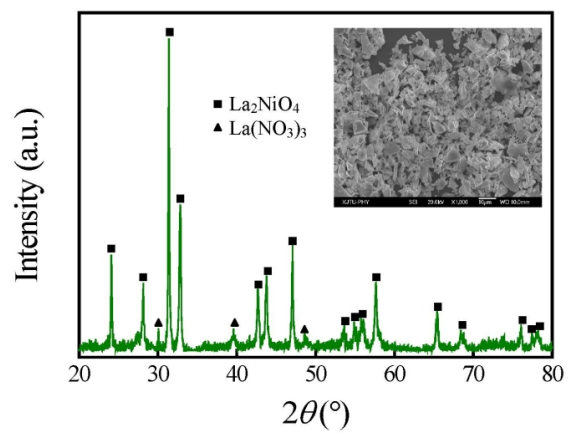

Fig. 1 XRD pattern and SEM image (the inset) of sol-gel-derived $\mathrm{La}_{2} \mathrm{NiO}_{4}$ particles.

Phase and Microstructure of $\mathrm{Cu} / \mathrm{La}_{2} \mathrm{NiO}_{4}$ Composites. Fig. 2 presents the XRD pattern of the hot-pressed $\mathrm{Cu} / \mathrm{La}_{2} \mathrm{NiO}_{4}$ composites. The very strong peaks are attributed to $\mathrm{Cu}$ matrix, and the small content of $\mathrm{La}_{2} \mathrm{NiO}_{4}$ results in its weak peaks, while slight oxygen contamination may present during sample preparation for the possible presence of $\mathrm{Cu}_{2} \mathrm{O}$. The results indicate that the addition of $5 \mathrm{wt} . \%$ $\mathrm{La}_{2} \mathrm{NiO}_{4}$ particles just weakly affects the composition of $\mathrm{Cu}$ base. The inset is the SEM image of the composites, demonstrating dispersed $\mathrm{La}_{2} \mathrm{NiO}_{4}$ particles in continuous $\mathrm{Cu}$ matrix.

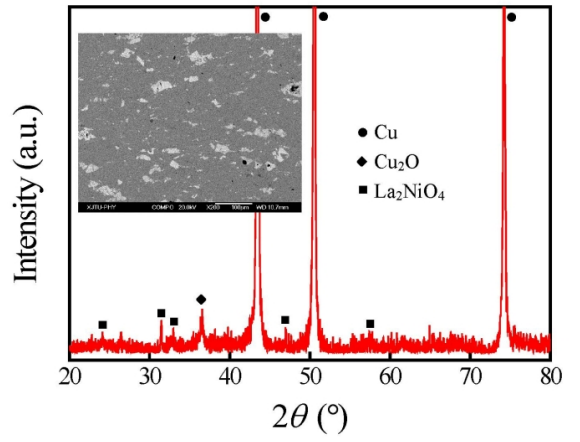

Fig. 2 XRD pattern and SEM image (the inset) of $\mathrm{Cu} / \mathrm{La}_{2} \mathrm{NiO}_{4}$ composites.

Electrical Contact Performance of $\mathrm{Cu} / \mathrm{La}_{2} \mathrm{NiO}_{4}$ Composites. Fig. 3(a) shows the electrical conductivity of $\mathrm{Cu} / \mathrm{La}_{2} \mathrm{NiO}_{4}$ composites and pure $\mathrm{Cu}$, revealing the conductivity of $85 \%$ and $98 \%$ IACS, respectively. The value for adding $\mathrm{La}_{2} \mathrm{NiO}_{4}$ into $\mathrm{Cu}$ is higher than that for other incorporations, reported in Ref. [1,6,10,11], whose values are in an approximate range of $11.8-81.9 \%$ IACS, though different fabrication conditions such as the variety (e.g., $\mathrm{TiB}_{2}, \mathrm{Y}_{2} \mathrm{O}_{3}, \mathrm{ZrC}, \mathrm{ZnO}, \mathrm{Al}_{2} \mathrm{O}_{3}$ ) and content (e.g., $0.5-6.0 \mathrm{wt} . \%$ or $1-2$ vol. $\%$ ) of reinforcements. The continuously distributed $\mathrm{Cu}$ matrix acts as a high-performance pathway for electrical conduction, and primarily determines the overall conductivity of the composites; meanwhile, $\mathrm{La}_{2} \mathrm{NiO}_{4}$ conductive ceramic reduces the electrical resistance originated from the second phase in conventional cases. 

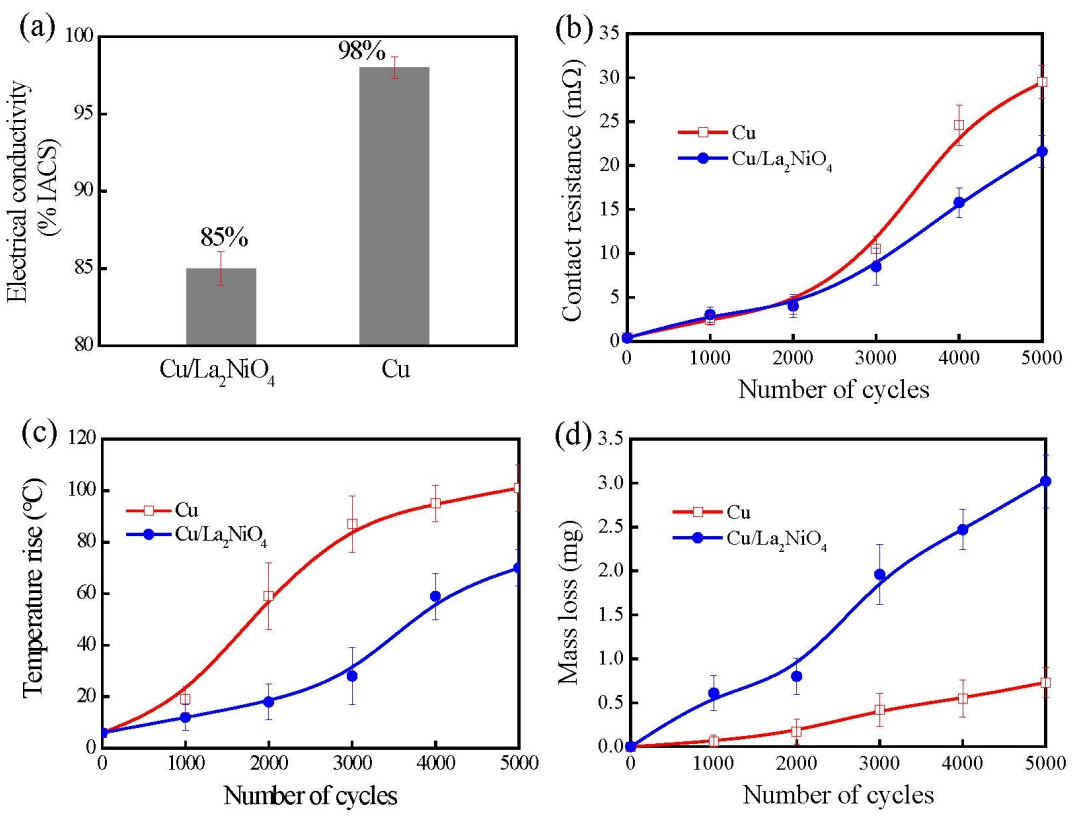

Fig. 3 Electrical conductivity (a) of $\mathrm{Cu} / \mathrm{La}_{2} \mathrm{NiO}_{4}$ and $\mathrm{Cu}$ contacts as well as contact resistance (b), temperature rise (c) and mass loss (d) of both during arc erosion test.

Figs. 3(b) - (d) present the electrical contact performance of $\mathrm{Cu} / \mathrm{La}_{2} \mathrm{NiO}_{4}$ composites during arc erosion test, and compared with that of pure $\mathrm{Cu}$. As shown in Fig. 3(b), both materials display similar contact resistance at the first 2000 cycles; but, subsequently, $\mathrm{Cu} / \mathrm{La}_{2} \mathrm{NiO}_{4}$ composites display rather smaller resistances than $\mathrm{Cu}$ contacts. The resistance decreases about $19.5 \%-35.8 \%$ from 3000 to 5000 cycles. The temperature rise of $\mathrm{Cu} / \mathrm{La}_{2} \mathrm{NiO}_{4}$ is also smaller than that of pure $\mathrm{Cu}$ (Fig. 3(c)), which declines roughly $30.7 \%-69.5 \%$; and moreover, the remarkable decline appears around 2000 cycles, approximating to the threshold of contact resistance decrease, shown in Fig. 3(b). More importantly, the mass loss for $\mathrm{Cu} / \mathrm{La}_{2} \mathrm{NiO}_{4}$ is significantly larger than that for pure $\mathrm{Cu}$, which differs from the common results demonstrated in $\mathrm{Cu}$ contacts strengthened with particle reinforcements to prevent mass loss. As reported by Güler and E. Evin [6], an introduction of $\mathrm{ZnO}, \mathrm{Al}_{2} \mathrm{O}_{3}$ and $\mathrm{Y}_{2} \mathrm{O}_{3}$ particles into $\mathrm{Cu}$ causes significant decreases of mass loss compared with pure one by arc erosion testing 3000, 6000 and 9000 counts. In detail, the mass loss of $\mathrm{Cu} / \mathrm{La}_{2} \mathrm{NiO}_{4}$ composites is about $0.55,0.63,1.54,1.92$, $2.29 \mathrm{mg}$ larger than that of pure $\mathrm{Cu}$ after 1000, 2000, 3000, 4000 and 5000 counts, implying accelerated removal of oxide scales from contact surface in service.

Arc-Erosion Behavior of $\mathrm{Cu} / \mathrm{La}_{2} \mathrm{NiO}_{4}$ Composites. Figs. 4(a) and (b) show the SEM image of the surface morphology of $\mathrm{Cu} / \mathrm{La}_{2} \mathrm{NiO}_{4}$ composites after 5000 cycles, exhibiting solidified droplets, cracks and pores derived from speedy melting and solidification due to arc erosion. Fig. 4(c) presents the XRD pattern of the sample, indicating $\mathrm{Cu}_{2} \mathrm{O}$ as the product after thousands of cycles of test. Fig. 4(d) shows the corresponding cross-sectional SEM image, apparently displaying two different areas in oxide layer, pointed by arrow 1 and 2, while their enlarged views are shown in Figs. 4(e) and (f). For area 1, a thinner scale is well bonded with substrate; however, a thicker scale is isolated from substrate by a crack passing through the scale/substrate interface in area 2 . Besides, it is noticeable that the significant difference between both areas is whether $\mathrm{La}_{2} \mathrm{NiO}_{4}$ particles present at scale/substrate interface, schematically illustrated by the insets in Fig. 4(e) and (f).

It is a well-established fact that the generation of oxide is consequent on arc erosion during switching on and off $\mathrm{Cu}$ based contacts in air, while stress applies on scales due to the contact force, conducing to the fracture of the brittle scale and mainly causing mass loss [6]. Therefore, the growth of scale layers is a dynamic process of oxide generation and separation; nevertheless, the generation rate is usually larger than the separation rate, so that the layer continuously thickens to an unacceptable contact resistance. In conventional cases, the reinforcements significantly impede the isolation of 
scales, indicated by decreased mass loss for $\mathrm{ZnO}, \mathrm{Al}_{2} \mathrm{O}_{3}$ and $\mathrm{Y}_{2} \mathrm{O}_{3}$ reinforced $\mathrm{Cu}$ contacts [6]. It therefore forms a thick scale layer to prevent or weaken further arc erosion of the inner part of contact materials; but the layer, producing high contact resistance and large temperature rise, deteriorates the performance stability of switches as well. For $\mathrm{Cu} / \mathrm{La}_{2} \mathrm{NiO}_{4}$ composites, on the other hand, $\mathrm{La}_{2} \mathrm{NiO}_{4}$ particle at scale/substrate interface plays a role in initiating crack to enhance the partial removal of scale layers, assumed by a comparison between Figs. 4(e) and (f), thus achieving self-cleaning-like function during cycling without any accessional aid, and also the small contact resistance and temperature rise. Finally, practical uses for the function can be also realized owing to the similar conditions between the arc erosion test and the service as well as the low cost of $\mathrm{Cu}$ compared with $\mathrm{Ag}$ base.
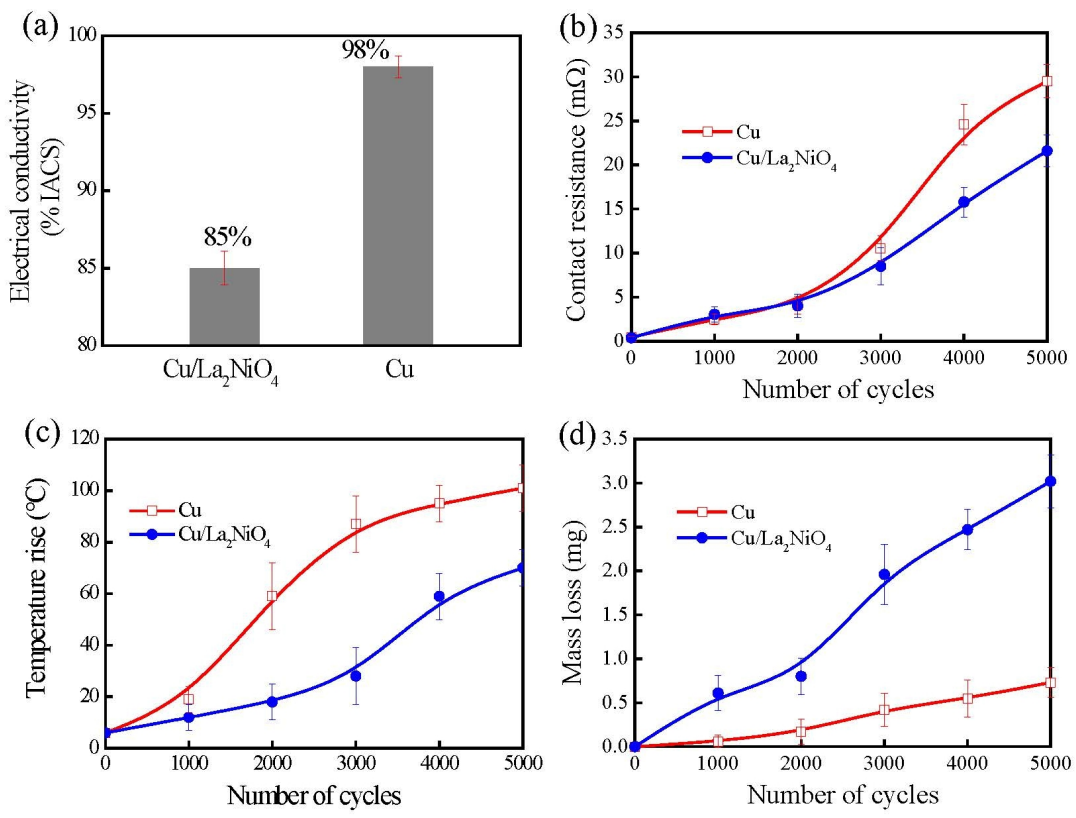

Fig. 4 (a), (b) SEM images of the surface morphology of $\mathrm{Cu} / \mathrm{La}_{2} \mathrm{NiO}_{4}$ composites after 5000 cycles; (c) The corresponding XRD pattern; (d) The corresponding cross-sectional SEM image; (e), (f) Enlarged views of area 1 and 2 pointed by arrows in Fig. 4(d), whose insets demonstrate schematic illustrations for the origin of self-cleaning-like functions.

\section{Conclusions}

The hot-pressed $\mathrm{Cu} / \mathrm{La}_{2} \mathrm{NiO}_{4}$ composites present a high bulk conductivity, $85 \%$ IACS, while their contact resistance decreases $19.5 \%-35.8 \%$ during 5000 cycles in contrast with pure $\mathrm{Cu}$, and correspondingly the temperature rise degrades about $30.7 \%-69.5 \%$. The particles in the composites accelerate partial separation of oxide scales from contact surface during arc erosion cycling, like the self-cleaning functions, indicated by increased mass loss of roughly 3 to 9 times larger than $\mathrm{Cu}$, so that the contact resistance and temperature rise reduce for an enhanced performance in service.

\section{Acknowledgements}

The authors acknowledge the financial support of the National Science Foundation of China (No. 51171146 and 51101177), the Program for Key Science and Technology Innovative Research Team of Shaanxi Province (No. 2013KCT-05).

\section{References}

[1] Z. Mu, H.R. Geng, M.M. Li, G.L. Nie, J.F. Leng, Effects of $\mathrm{Y}_{2} \mathrm{O}_{3}$ on the property of copper based contact materials, Compos. B 52 (2013) 51-55. 
[2] P.G. Slade, Advances in material development for high power, vacuum interrupter contacts, IEEE Trans. Compon. Pack. Manuf. Technol. A 17 (1994) 96-106.

[3] H. Fink, D. Gentsch, M. Heimbach, Multilayer contact material based on copper and chromium material and its interruption ability, IEEE Trans. Plasma Sci. 31 (2003) 973-976.

[4] M. Aindow, S.P. Alpay, Y. Liu, J.V. Mantese, B.S. Senturk, Base metal alloys with self-healing native conductive oxides for electrical contact materials, Appl. Phys. Lett. 97 (2010) 152103.

[5] L. Lu, Y.F. Shen, X.H. Chen, L.H. Qian, K. Lu, Ultrahigh strength and high electrical conductivity in copper, Science 304 (2004) 422-426.

[6] Ö. Güler, E. Evin, The investigation of contact performance of oxide reinforced copper composite via mechanical alloying, J. Mater. Process. Technol. 209 (2009) 1286-1290.

[7] R.R. Schartman, J.M. Honig, Magnetic susceptibility investigations of the $\mathrm{La}_{2} \mathrm{NiO}_{4}+\delta$ system, Mater. Res. Bull. 24 (1989) 671-679.

[8] C.L. Guo, X.L. Zhang, J.L. Zhang, Y.P. Wang, Preparation of $\mathrm{La}_{2} \mathrm{NiO}_{4}$ catalyst and catalytic performance for partial oxidation of methane, J. Molecular Catal. A 269 (2007) 254-259.

[9] J. Wang, D.M. Li, Y.P. Wang, Microstructure and properties of Ag- $\mathrm{SnO}_{2}$ materials with high $\mathrm{SnO}_{2}$ content, J. Alloys Compd. 582 (2014) 1-5.

[10] M. López, D.Corredor, C. Camurri, V. Vergara, J. Jiménez, Performance and characterization of dispersion strengthened $\mathrm{Cu}-\mathrm{TiB}_{2}$ composite for electrical use, Mater. Charact. 55 (2005) 252-262.

[11] M. López, J.A. Jiménez, D.Corredor, Precipitation strengthened high strength-conductivity copper alloys containing ZrC ceramics, Compos. A 38 (2007) 272-279. 